\title{
What Is the Smallest Saturated Acyclic Alkane that Cannot Be Made?
}

\author{
K. M. Nalin de Silva ${ }^{\dagger}$ and Jonathan M. Goodman* \\ Department of Chemistry, Unilever Centre for Molecular Science Informatics, Lensfield Road, \\ Cambridge CB2 1EW, U.K.
}

Received July 28, 2004

\begin{abstract}
Saturated acyclic alkanes may show a high degree of strain if they have many branches close to each other. We report calculations which indicate how strained a molecule may become before it falls apart rapidly at room temperature and so allow us to identify the simplest alkane which cannot be made.
\end{abstract}

\section{INTRODUCTION}

Earlier studies on acyclic alkane conformations ${ }^{1,2}$ lead us to the question of the simplest acyclic unbranched alkane that cannot be made. In this paper we examine molecules that do not look extraordinary but, nevertheless, could not be made. Extraordinary molecules can be made and analyzed at very low temperatures for the brief time before they decompose. Here we consider only molecules that can be made and stored at room temperature. An issue of Chemical Reviews that focused on strained organic compounds limited its discussions to cyclic species. ${ }^{3}$ However, neighboring quaternary centers are likely to lead to strained structures. ${ }^{4}$ Thus, alkanes may be very strained, even without rings, as multiple branching pushes side chains close together. The series $\mathrm{C}\left(\mathrm{CH}_{3}\right)_{4}, \mathrm{C}\left(\mathrm{C}\left(\mathrm{CH}_{3}\right)_{3}\right)_{4}, \mathrm{C}\left(\mathrm{C}\left(\mathrm{C}\left(\mathrm{CH}_{3}\right)_{3}\right)_{3}\right)_{4}$, and $\mathrm{C}(\mathrm{C}(\mathrm{C}(\mathrm{C}$ $\left.\left.\left.\left(\mathrm{CH}_{3}\right)_{3}\right)_{3}\right)_{3}\right)_{4}$ gets increasingly crowded and hard to draw (Figure 1). At each level of branching, it becomes more difficult to add additional methyl groups because the number of methyl groups that need to be fitted in doubles with every shell, whereas the surface area only increases with the square of the radius of the molecule. At some point, the strain in the molecule will be sufficient to break a carbon-carbon bond, and so it will be impossible to synthesize the molecule.

Molecule 2 (Figure 1) has never been synthesized, and studies have shown that it must be extremely strained. ${ }^{5-7}$ However, this is not a proof that it is impossible to prepare. Indeed, molecules which include this carbon framework, such as tetramethyltetrabenzo[5,5,5,5]fenestrane (5, Figure 2), have been synthesized. ${ }^{8}$ This is a less strained molecule than 2 , as some adjacent carbon atoms have $\mathrm{C}-\mathrm{C}$ bonds connecting them and do not need to fit two $\mathrm{C}-\mathrm{H}$ bonds in the same space. However, the existence of such molecules suggest that the preparation of 2 may be possible. In this paper, we have tried to place limits on the simplest acyclic alkane that can never be made.

Some rather strained molecules have been made. Both $6^{9}$ and $7^{10}$ (Figure 2) have been reported. Molecule 8 is listed in Beilstein but appears not to have been made. Molecule 9 was reported in $1934^{11}$ although the identification was questioned in $1942^{12}$ and has since been shown to be

\footnotetext{
* Corresponding author e-mail: J.M.Goodman@ch.cam.ac.uk.

Department of Chemistry, University of Colombo, P.O. Box 1490, Colombo 03, Sri Lanka.
}
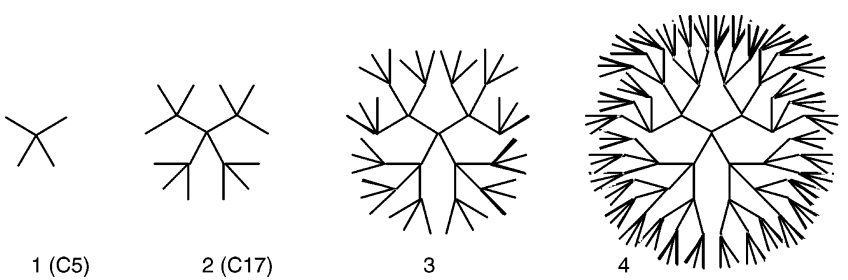

Figure 1. Increasing steric demands for branched molecules.

incorrect. ${ }^{13}$ In this highly branched series, the simplest alkane that has never been made, is, so far as we can discover, 10.

We have followed four approaches to answering the question of the title. First, we analyze the increasing costs of adding new alkyl groups to a structure. Second, we analyze structures that cannot fit on a diamond lattice, extending the analysis of Klein. ${ }^{13}$ Third, we apply Rüchardt's observation ${ }^{8}$ of a correlation between strain energy and thermal stability for alkanes. Finally, we analyze candidate structures using DFT methods.

\section{RESULTS AND DISCUSSION}

(i) The Cost of Adding Tertiary Butyl Groups. Our first investigations used molecular mechanics: MM2 $2^{15}$ as implemented in MacroModel version $5.5^{16}$ using Monte Carlo conformation searches ${ }^{17}$ wherever the molecules had flexible torsion angles. The series of structures shown in Figure 3 were studied first. In this series, the most hindered methyl group of each molecule is replaced by a tertiary butyl group in order to generate the next structure. The molecules are labeled according to the number of carbon atoms, and so molecules 1, 2, 6, and 10 from Figures 1 and 2 are here labeled $\mathrm{C} 5, \mathrm{C} 17, \mathrm{C} 11$, and $\mathrm{C} 14$, respectively. We were surprised to note that some of these molecules have multiple nonsymmetry-related minima in their potential energy surfaces, despite their high symmetry. The energy of 2,2dimethylpropane (C5) is $9.50 \mathrm{~kJ} \mathrm{~mol}^{-1}$. This is $2.31 \mathrm{~kJ} \mathrm{~mol}^{-1}$ lower in energy than its isomer $n$-pentane and $6 \mathrm{~kJ} \mathrm{~mol}^{-1}$ higher in energy than ethane. The results are given in Table 1 , both for the MM2 calculations and for AM1 ${ }^{18,19}$ reminimizations of the lowest energy structures found using MM2. In the cases where several conformations were found, the energies are given for the global minima.

The MM2 calculations show that it becomes increasingly difficult to add extra tertiary butyl groups to the structures 

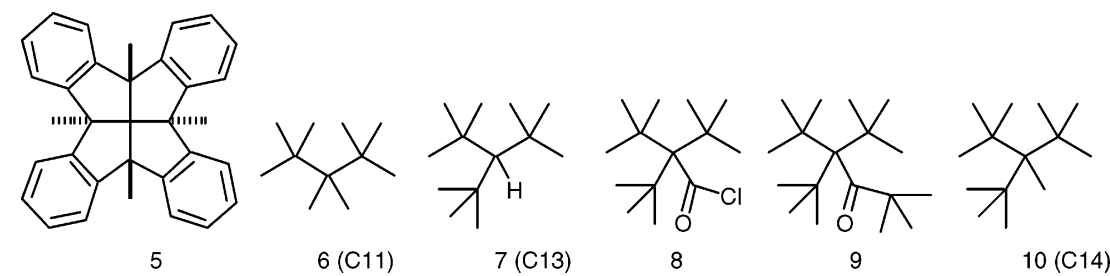

Figure 2. Strained molecules that have been reported (5-9) and an unreported molecule (10).
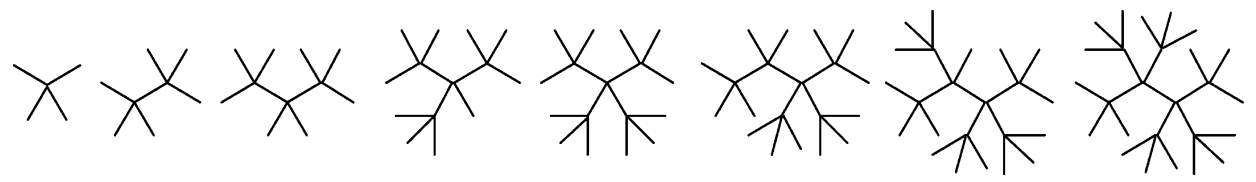

C5 C8

C11

C14

C17

C20

C23

C26

Figure 3. Alkanes with increasing numbers of tertiary butyl groups.

Table 1. Molecular Mechanics and AM1 Energies for Eight Alkanes

\begin{tabular}{|c|c|c|c|c|c|c|}
\hline structure & $\begin{array}{c}\text { energy } \\
\left(\mathrm{kJ} \mathrm{mol}^{-1}\right) \\
\mathrm{MM} 2\end{array}$ & $\begin{array}{l}\text { cost of adding } \\
\mathrm{t}-\mathrm{Bu}\left(\mathrm{kJ} \mathrm{mol}^{-1}\right)\end{array}$ & $\begin{array}{c}\text { incremental } \\
\text { cost of t-Bu } \\
\left(\mathrm{kJ} \mathrm{mol}^{-1}\right)\end{array}$ & $\begin{array}{c}\text { energy } \\
\left(\mathrm{kJ} \mathrm{mol}^{-1}\right) \\
\mathrm{AM} 1\end{array}$ & $\begin{array}{l}\text { cost of adding } \\
\mathrm{t}-\mathrm{Bu}\left(\mathrm{kJ} \mathrm{mol}^{-1}\right)\end{array}$ & $\begin{array}{c}\text { incremental } \\
\text { cost of t-Bu } \\
\left(\mathrm{kJ} \mathrm{mol}^{-1}\right)\end{array}$ \\
\hline $\mathrm{C} 5$ & 9.50 & 6.09 & & -137.29 & -64.32 & \\
\hline C8 & 51.13 & 41.63 & 35.54 & -167.22 & -29.93 & 34.39 \\
\hline $\mathrm{C} 11$ & 140.99 & 89.86 & 48.23 & -147.62 & 19.60 & 49.53 \\
\hline $\mathrm{C} 14$ & 254.00 & 113.01 & 23.15 & -86.08 & 61.54 & 41.94 \\
\hline $\mathrm{C} 17$ & 460.46 & 206.46 & 93.45 & 84.38 & 170.46 & 108.92 \\
\hline $\mathrm{C} 20$ & 661.61 & 201.15 & -5.31 & 183.51 & 99.13 & -71.33 \\
\hline $\mathrm{C} 23$ & 981.71 & 320.10 & 118.95 & 229.43 & 45.92 & -53.21 \\
\hline $\mathrm{C} 26$ & 1423.01 & 441.30 & 121.2 & 244.08 & 14.65 & -31.27 \\
\hline
\end{tabular}

as the size of the molecules increases. This extra strain energy is spread out through the molecule and not concentrated in a single bond. MM2 does not allow bonds to break, and so the structures are forced to hold together, despite great distortions. The column showing the cost of adding each new tertiary butyl group indicates that the energy required increases as the structure becomes more crowded. The third column, the incremental cost, is the difference between successive values of the second column. This is particularly large for squeezing the final tertiary butyl group into the shell to make $\mathrm{C} 17$, and then much smaller for $\mathrm{C} 20$, adding the first component of the next shell. C17, therefore, will be a particularly difficult molecule to make, and if it can be made, rather larger molecules may well be accessible too.

The AM1 semiempirical molecular orbital method gives very different results in the first two columns, as the energy of three extra methyl groups is now negative instead of positive. AM1 calculations were carried out on the global minimum structures from the MM2 conformation searches. This systematic difference between AM1 and MM2 cancels in the third column (incremental cost), which shows a pattern similar to MM2 up to C17. After this point the change is dramatic, as AM1 allow the bonds to break as well as to stretch. C20 has a minimum as a single molecule, but both C23 and C26 break up into a pair of radicals, and we could find no minimum in the AM1 potential energy surface that corresponded to a single molecule. This calculation suggests that $\mathrm{C} 20$ can probably be made, and C23 is the smallest saturated alkane of this series that cannot be made. AM1 is not a sufficiently high-level method to draw a firm conclusion from this result alone. However, we decided to focus our study on molecules smaller than $\mathrm{C} 26$, on the basis of this information, and to look at these smaller structures in more detail.
Figure 4 shows the list of structures we now considered, again labeled according to the number of carbon atoms they contain. The boxed structures are the highest energy isomers we have found for each molecular formula. They were constructed first ensuring the maximum number of quaternary carbon atoms, then the minimum number of bonds linking the most distance atoms in the structure, and finally the maximum number of tertiary carbon atoms. The remaining structures are highly strained but do not fit so neatly into the series.

The results of a systematic study of all the alkanes shown in Figure 4 using MM2, MMFF, ${ }^{20}$ and AM1 are presented in Table 2. The energies and bond lengths for the MM2, MMFF, and AM1 calculations show the same trends in all cases, except for the AM1 calculations in which the bonds break altogether, which occurs when the MM2 bond length exceeds $1.70 \AA$ and the MMFF bond length exceeds 1.86 $\AA$. These data suggest that neither $\mathrm{C} 22$ nor $\mathrm{C} 22 \mathrm{~A}$ can be made and that $\mathrm{C} 21$ is on the edge of stability, consistent with the results in Table 1.

For all methods of energy calculation, the hardest methyl groups to add are the ones which complete tertiary butyl groups. Thus the transitions from $\mathrm{C} 16$ to $\mathrm{C} 17, \mathrm{C} 19$ to $\mathrm{C} 20$, and $\mathrm{C} 22$ to $\mathrm{C} 23$ have particularly large energy increases. This suggests that $\mathrm{C} 17, \mathrm{C} 20$, and $\mathrm{C} 23$ will be particularly hard to make, and so the limit of stability may occur just before one of these structures.

(ii) Klein Overlap Analysis. Klein ${ }^{14}$ has analyzed the smallest alkanes for which it is not possible to position all of the carbon atoms on a diamond lattice without overlap. Any molecule which fails this test is clearly very strained, but it is not clear that all such molecules will be impossible to make, nor that all molecules for which the carbon atoms can fit on a diamond lattice can be made. The carbon atoms 


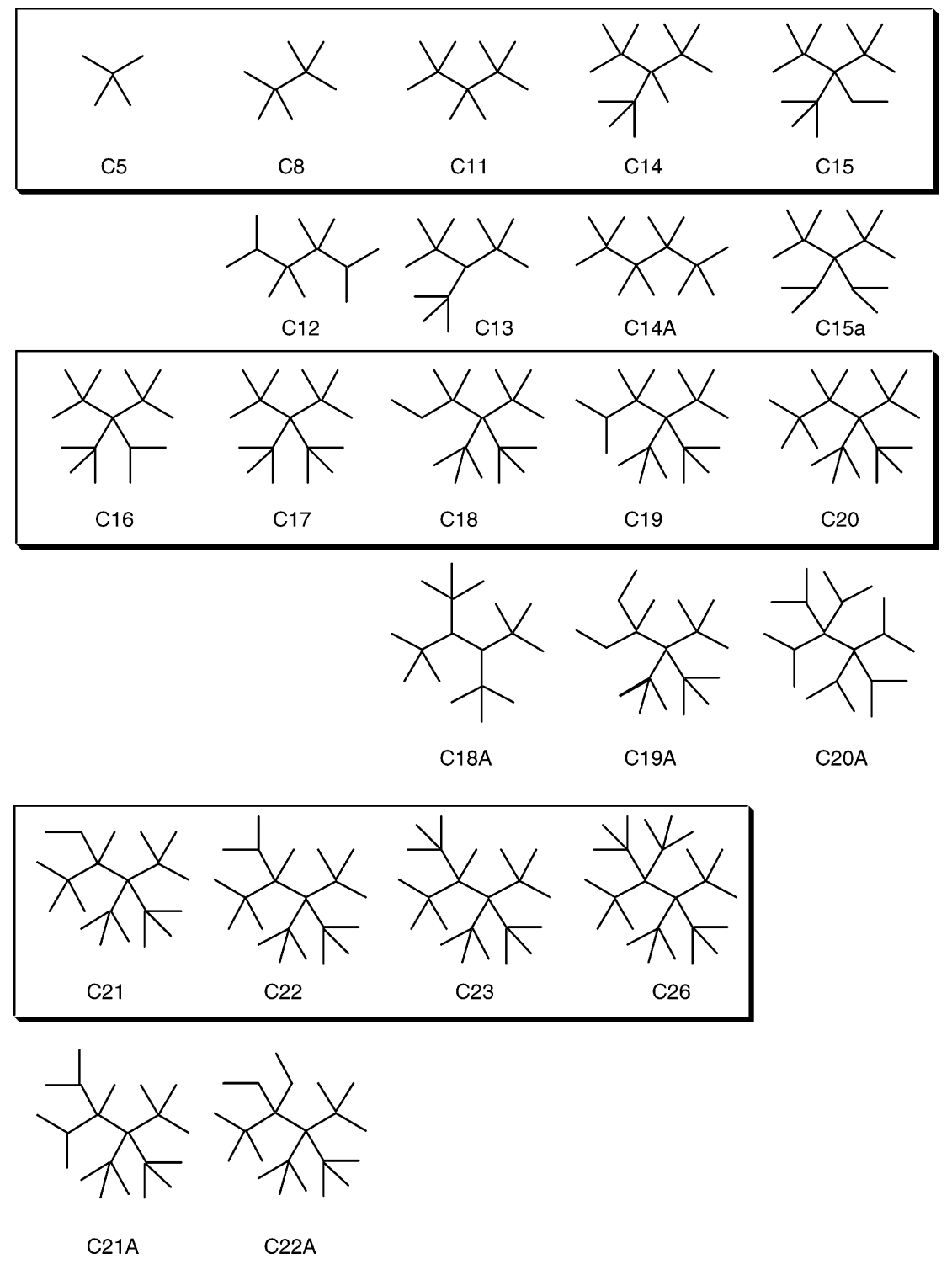

Figure 4. Sequence of strained alkanes, labeled by number of carbon atoms.

of tetra-tert-butylmethane (2, Figure 1, and C17, Figure 3), for example, can be fitted on a diamond lattice, but the molecule has never been made. This point was made by Davies and Freyd ${ }^{21}$ who were concerned with counting alkane isomers and derived a formula which enabled them to count acyclic alkane isomers excluding the substructure $\mathrm{C}\left(\mathrm{C}\left(\mathrm{CH}_{3}\right)_{3}\right)_{4}$ corresponding to $\mathrm{C} 17$.

Klein presented the four structures shown in Figure 5 as the four basic forbidden trees, none of which can be embedded on a tetrahedral lattice, although every subtree of each can. These structures were analyzed using MM2 and MMFF conformation searches and AM1 calculations on the MM2 global minimum. The results are given in Table 3. It is clear from the table that these structures are less strained than the smaller structures C22 and C21 (Table 2). K23 is more than $400 \mathrm{~kJ} \mathrm{~mol}^{-1}$ lower in energy than $\mathrm{C} 23$, according to both MM2 and MMFF, and the AM1 calculation finds a structure for which none of the $\mathrm{C}-\mathrm{C}$ bonds have broken. The reason for this is that the $\mathrm{C}-\mathrm{CH}_{2}-\mathrm{C}$ bond angle is able to open out to relieve the steric strain. On the basis of their longest $\mathrm{C}-\mathrm{C}$ bonds, the strain in these molecules is closer to that of $\mathrm{C} 17$ than of $\mathrm{C} 23$. It is clear, therefore, that these structures do not represent the smallest saturated alkanes that cannot exist.

(iii) Ruichardt Analysis. Rüchardt has shown that the strain energy of alkanes shows a linear relationship with the activation free energy for thermolysis. ${ }^{9}$ More recent results from the same group have shown that MM2 calculations give reasonable results when used to calculate the enthalpy of formations of sterically congested hydrocarbons, ${ }^{22}$ and Dubois has shown that MM2 also works well to estimate activation energies for the thermolysis of highly congested carbinols. ${ }^{23}$ If a molecule undergoes thermolysis at room temperature with a half-life of less than an hour, it seems reasonable for one to say that such a molecule cannot be made and stored.

Using Rüchardt's experimental results, we first verified that MM2 also showed a linear relationship with thermal stability, for the five structures on the left-hand side of Table 4. We calculated the strain energy by subtracting the energy of a linear unbranched isomer of the alkane from the energy of the strained alkane to find $E_{\mathrm{S}}$. Our correlation coefficient was slightly smaller than that reported by Rüchardt, who was using a different force field, but the correlation appeared 
Table 2. Molecular Mechanics and Semiempirical Energies for the Alkanes

\begin{tabular}{|c|c|c|c|c|c|c|}
\hline structure & $\begin{array}{c}\text { energy } \\
\left(\mathrm{kJ} \mathrm{mol}^{-1}\right) \\
\text { MM2 }\end{array}$ & $\begin{array}{c}\text { longest } \mathrm{C}-\mathrm{C} \\
\text { bond }(\AA) \\
\text { MM2 }\end{array}$ & $\begin{array}{c}\text { energy } \\
\left(\mathrm{kJ} \mathrm{mol}^{-1}\right) \\
\mathrm{MMFF}^{2}\end{array}$ & $\begin{array}{c}\text { longest } \mathrm{C}-\mathrm{C} \\
\text { bond }(\AA) \\
\mathrm{MMFF}\end{array}$ & $\begin{array}{c}\text { energy } \\
\left(\mathrm{kJ} \mathrm{mol}^{-1}\right) \\
\text { AM1 }\end{array}$ & $\begin{array}{c}\text { longest } \mathrm{C}-\mathrm{C} \\
\text { bond }(\AA) \\
\text { AM1 }\end{array}$ \\
\hline $\mathrm{C} 5$ & 9.50 & 1.541 & 35.57 & 1.535 & -137.29 & 1.521 \\
\hline $\mathrm{C} 8$ & 51.13 & 1.574 & 124.53 & 1.597 & -167.22 & 1.547 \\
\hline C11 & 140.99 & 1.596 & 259.24 & 1.635 & -147.62 & 1.563 \\
\hline $\mathrm{C} 12$ & 130.16 & 1.598 & 249.71 & 1.651 & -203.42 & 1.567 \\
\hline $\mathrm{C} 13$ & 195.06 & 1.601 & 368.56 & 1.646 & -138.73 & 1.563 \\
\hline $\mathrm{C} 14$ & 254.00 & 1.619 & 426.64 & 1.692 & -86.08 & 1.583 \\
\hline C14A & 214.90 & 1.614 & 415.46 & 1.680 & -139.85 & 1.581 \\
\hline C15 & 307.42 & 1.627 & 522.10 & 1.718 & -67.16 & 1.596 \\
\hline $\mathrm{C} 15 \mathrm{~A}$ & 294.89 & 1.617 & 490.50 & 1.690 & -93.65 & 1.582 \\
\hline $\mathrm{C} 16$ & 376.59 & 1.634 & 618.28 & 1.737 & -8.79 & 1.604 \\
\hline $\mathrm{C} 17$ & 460.46 & 1.643 & 739.51 & 1.752 & 84.38 & 1.613 \\
\hline C18 & 487.68 & 1.650 & 762.76 & 1.774 & 80.25 & 1.624 \\
\hline C18A & 300.84 & 1.605 & 588.17 & 1.669 & -111.56 & 1.577 \\
\hline C19 & 555.03 & 1.661 & 861.63 & 1.803 & 123.76 & 1.650 \\
\hline C19A & 522.73 & 1.657 & 797.33 & 1.793 & 83.83 & 1.640 \\
\hline $\mathrm{C} 20$ & 661.61 & 1.681 & 1012.66 & 1.839 & 183.51 & 1.709 \\
\hline C20A & 493.00 & 1.659 & 739.71 & 1.855 & -25.97 & 1.756 \\
\hline $\mathrm{C} 21$ & 705.19 & 1.691 & 1059.79 & 1.856 & 241.42 & 2.111 \\
\hline $\mathrm{C} 21 \mathrm{~A}$ & 680.47 & 1.690 & 1026.54 & 1.853 & 202.19 & 1.846 \\
\hline $\mathrm{C} 22$ & 784.57 & 1.706 & 1168.34 & 1.880 & 181.53 & 4.404 \\
\hline $\mathrm{C} 22 \mathrm{~A}$ & 775.55 & 1.705 & 1135.13 & 1.881 & 154.42 & 4.345 \\
\hline $\mathrm{C} 23$ & 981.71 & 1.735 & 1415.18 & 1.909 & 229.43 & 4.707 \\
\hline C26 & 1423.01 & 1.777 & 1915.91 & 1.957 & 244.08 & 5.575 \\
\hline
\end{tabular}

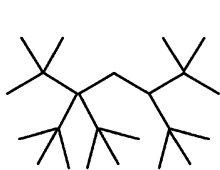

K23

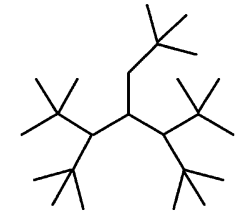

$\mathrm{K} 24 \mathrm{a}$

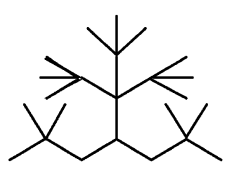

$\mathrm{K} 24 \mathrm{~b}$

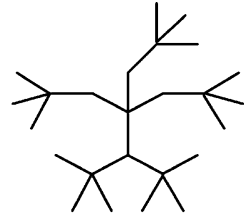

K25

Figure 5. Klein's minimal structures that cannot fit on a diamond lattice.

Table 3. Klein's Minimal Nondiamond Lattice Structures

\begin{tabular}{|c|c|c|c|c|c|c|}
\hline & $\begin{array}{c}\text { energy } \\
\left(\mathrm{kJ} \mathrm{mol}^{-1}\right) \\
\text { MM2 }\end{array}$ & $\begin{array}{c}\text { longest } \mathrm{C}-\mathrm{C} \\
\text { bond }(\AA) \\
\mathrm{MM} 2\end{array}$ & $\begin{array}{c}\text { energy } \\
\left(\mathrm{kJ} \mathrm{mol}^{-1}\right) \\
\text { MMFF }\end{array}$ & $\begin{array}{c}\text { longest } \mathrm{C}-\mathrm{C} \\
\text { bond }(\AA) \\
\text { MMFF }\end{array}$ & $\begin{array}{c}\text { energy } \\
\left(\mathrm{kJ} \mathrm{mol}^{-1}\right) \\
\mathrm{AM} 1\end{array}$ & $\begin{array}{c}\text { longest } \mathrm{C}-\mathrm{C} \\
\text { bond }(\AA) \\
\text { AM1 }\end{array}$ \\
\hline K23 & 520.72 & 1.639 & 896.97 & 1.748 & -33.34 & 1.615 \\
\hline $\mathrm{K} 24 \mathrm{a}$ & 383.58 & 1.653 & 749.10 & 1.674 & -201.46 & 1.581 \\
\hline $\mathrm{K} 24 \mathrm{~b}$ & 528.68 & 1.645 & 898.01 & 1.771 & -58.22 & 1.621 \\
\hline K25 & 432.92 & 1.631 & 820.53 & 1.746 & -175.10 & 1.608 \\
\hline
\end{tabular}

Table 4. MM2 Calculated Strain Energies $\left(E_{\mathrm{s}}\right)$, Free Energies for Thermolysis, and Decomposition Temperatures for a Half-Life of $1 \mathrm{~h}$

\begin{tabular}{|c|c|c|c|c|c|c|c|}
\hline & $\begin{array}{c}E_{\mathrm{s}} \\
\left(\mathrm{kJ} \mathrm{mol}^{-1}\right)\end{array}$ & $\begin{array}{l}T\left({ }^{\circ} \mathrm{C}\right) \\
\text { exptl }\end{array}$ & $\begin{array}{c}\Delta G^{\ddagger} \\
\left(\mathrm{kJ} \mathrm{mol}^{-1}\right) \\
\operatorname{exptl}\end{array}$ & & $\begin{array}{c}E_{\mathrm{s}} \\
\left(\mathrm{kJ} \mathrm{mol}^{-1}\right)\end{array}$ & $\begin{array}{l}T\left({ }^{\circ} \mathrm{C}\right) \\
\text { calcd }\end{array}$ & $\begin{array}{c}\Delta G^{\ddagger} \\
\left(\mathrm{kJ} \mathrm{mol}^{-1}\right) \\
\text { calcd }\end{array}$ \\
\hline C8 & 31.17 & 490 & 253.1 & C15 & 268.44 & 89 & 104.8 \\
\hline $\mathrm{C} 11$ & 112.88 & 350 & 204.2 & $\mathrm{C} 16$ & 334.89 & -16 & 64.2 \\
\hline C12 & 99.33 & 329 & 194.1 & C17 & 416.05 & -145 & 15.9 \\
\hline $\mathrm{C} 14 \mathrm{~A}$ & 178.64 & 195 & 141.0 & $\mathrm{~K} 23$ & 460.01 & -215 & -10.3 \\
\hline \multirow[t]{3}{*}{ C18A } & 253.71 & 141 & 123.8 & $\mathrm{~K} 24 \mathrm{a}$ & 320.15 & 7 & 73.0 \\
\hline & & & & $\mathrm{K} 24 \mathrm{~b}$ & 465.25 & -223 & -13.4 \\
\hline & & & & $\mathrm{K} 25$ & 366.77 & -67 & 45.3 \\
\hline
\end{tabular}

to hold (Figure 6). Extrapolating beyond the end of the graph, we could now find the simplest alkane with a half-life of less than an hour at room temperature. The results are given in the table. $\mathrm{C} 15$ is predicted to have a half-life of an hour at $89{ }^{\circ} \mathrm{C}$, while $\mathrm{C} 16$ would only survive this long at -16 ${ }^{\circ} \mathrm{C}$, and $\mathrm{C} 17$ would require a temperature of $-145^{\circ} \mathrm{C}$. K23 and $\mathrm{K} 24 \mathrm{~b}$ are predicted to have negative free energies of activation, so it is clear that the linear extrapolation breaks down before this point.
The use of the molecular-mechanics calculated steric strain energy is only useful if the energy us quite evenly spread over the molecule, as it is for $\mathrm{C} 15, \mathrm{C} 16$, and $\mathrm{C} 17$, but is less likely to be true for K23 and K24b, which have a greater variety of environments around the carbon atoms. On the basis of this analysis, the smallest saturated alkane that cannot be made will be $\mathrm{C} 16$, as it would not exist for long enough to be bottled and stored at room temperature, although it may be possible to analyze it at very low temperatures. 
Rüchardt Analysis

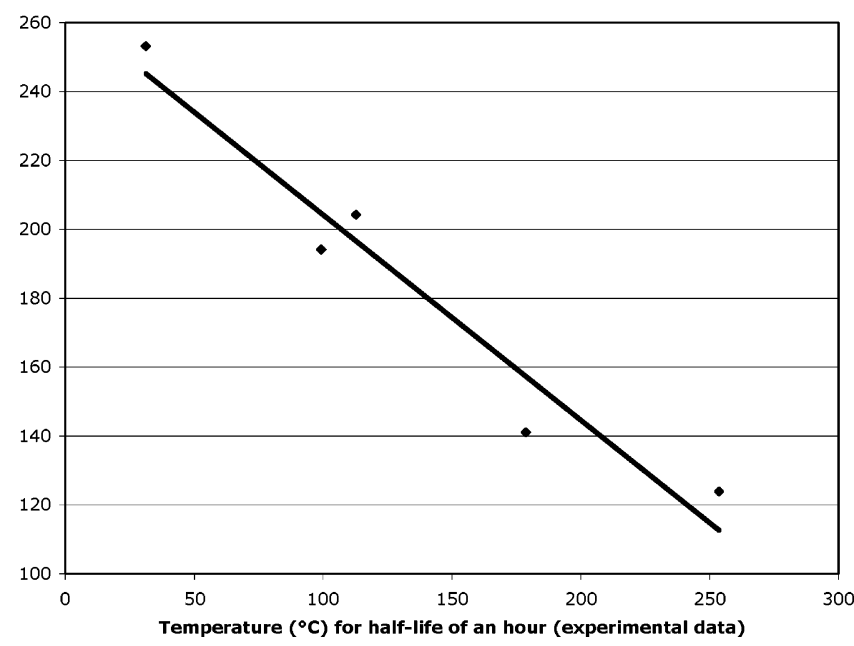

Figure 6. MM2 strain energy plotted against temperature for a half-life of $1 \mathrm{~h}$.

(iv) Relate Bond Lengths to Stability. The Rüchardt analysis considers the total energy of each molecule, and so may be misleading if the molecule has some unstrained regions and the energy is concentrated on a single bond. Table 2 suggests an alternative way of estimating whether a complex molecule will spontaneously dissociate or not. The longest carbon-carbon bond in the global minimum conformation, as calculated by a force field such as MM2, is both quick to calculate and an indication of the stability of the molecule. The longest carbon-carbon bonds are very similar for $\mathrm{C} 14$ and for C14A. Since C14A has been made, it seems likely that $\mathrm{C} 14$ could be made too. If the limit of stability is at $\mathrm{C} 15$, the longest bond for stability would be $1.63 \AA$ (MM2) and $1.72 \AA$ (MMFF), respectively. If the limit is as high as $\mathrm{C} 18$, molecules may be stable with bonds as long as $1.65 \AA$ (MM2) or $1.77 \AA$ (MMFF). No experimentally prepared acyclic alkane appears to have a carbon-carbon bond longer than this. In the MM2 force field, a carbon-carbon bond has to be stretched to $2.0 \AA$ to have a stretch energy of about $300 \mathrm{~kJ} \mathrm{~mol}^{-1}$, the amount required to break a carbon-carbon bond. The molecules are certainly unable to withstand this degree of stretching. This analysis of bond lengths suggests that $\mathrm{C} 15 \mathrm{~A}$ is much less strained than $\mathrm{C} 15$, consistent with the energy calculations.

Carbon-carbon bonds that are longer than this have been reported. A search through the Cambridge Crystallographic Database $^{24}$ found about 200 organic structures with $R<5 \%$, with no disorder, and with carbon-carbon bonds longer than $1.63 \AA$. These were all reminimized with the MM2 force field. About a quarter of the structures could not be minimized because they contained functional groups for which MM2 is not parametrized. Of the 146 that did minimize successfully, only one had a MM2 bond length of more than $1.63 \AA$. This structure has the CSD code HOLKOI, ${ }^{25}$ and its structure is shown in Figure 7 . The bond in the four-membered ring is $1.734 \AA$ long in the crystal structure and $1.647 \AA$ long after reminimization by MM2. The four-membered ring both stretches the bond and also prevents the bond from getting too long, since if the bond were to break, this molecule would not split into fragments and the radicals or ions formed might recombine. It is,
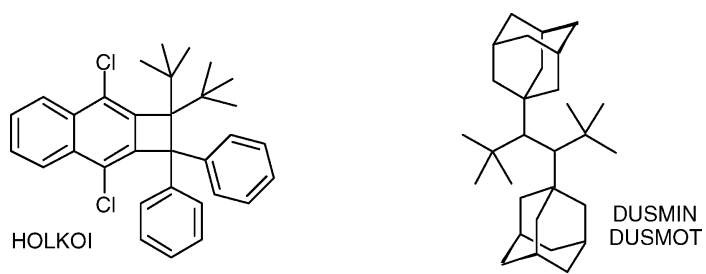

Figure 7. Structures from the CSD with extremely long carboncarbon bonds.

Table 5. Normal Mode Frequencies $\left(\mathrm{cm}^{-1}\right)$ Corresponding to the Longest Carbon-Carbon Bond Stretching

\begin{tabular}{cccccccc}
\hline ethane & C8 & C13 & C14 & C15 & C16 & C17 & C20 \\
\hline 1440 & 1278 & 890 & 842 & 877 & 843 & 749 & 552 \\
\hline
\end{tabular}

therefore, a rather different system to the acyclic alkanes considered in this paper. The longest acyclic carbon-carbon bond occurs in DUSMIN and DUSMOT (Figure 7; two different crystal structures for distinct rotamers of one molecule $\left.{ }^{26}\right)$. The central carbon-carbon bond is $1.634 \AA$ in the crystal structure and $1.611 \AA$ after MM2 reminimization, which is very similar to the value for the closely related structure C18A, which has a carbon-carbon distance of $1.605 \AA$ according to MM2. These data suggest that C14, with an MM2-calculated bond length of $1.619 \AA$, should probably exist.

(v) Quantum Chemistry Calculations. We now turned to a higher level of theory, B3LYP/6-31G** (UHF/UDFT), to give us further insights into the structure and stability of these alkanes, using the Jaguar program. ${ }^{27}$ The MM2 global minima were used as the starting point for the reminimizations, except where indicated.

Normal-mode frequency analyses were completed for ethane, C8, C13, C14, C15, C16, C17, and C20 and are listed in Table 5. The normal mode associated with stretching the longest carbon-carbon bond was calculated in each case. For the first five molecules, the normal mode with the largest component on a carbon-carbon bond corresponded to the longest carbon-carbon bond and the one chosen for the homolytic cleavage in the earlier analysis. In the case of C20, the normal modes were so complex, that the assignment was less clear. The frequency reported corresponds to stretching the longest bond in the molecule. The table shows that the bonds get progressively weaker as the bonds are stretched by the steric demands of the molecule, except for $\mathrm{C} 15$ for which the potential well for stretching the weakest bond was surprisingly steep.

The radical energies and structures are given in Figure 8 and Table 6. Table 7 gives the calculated energies of the systems, the longest carbon-carbon bond in the structure, and the energy relative to isolated radicals. In all cases, radicals chosen for comparison were tertiary, and this always corresponded to breaking the longest bond in the structure. Thus C16's energy is given relative to the sum of the energies of R4 and R12 and not to the sum of R3 and R13 (Figure 9).

For C22 and larger alkanes, there does not appear to be a minimum on the B3LYP/6-31G** potential energy surface which corresponded to a single molecule. Two different minima were found for $\mathrm{C} 20$, one for the single molecule and one for a radical pair, with the latter being much lower in energy. The cases where the alkanes are present as radicals 


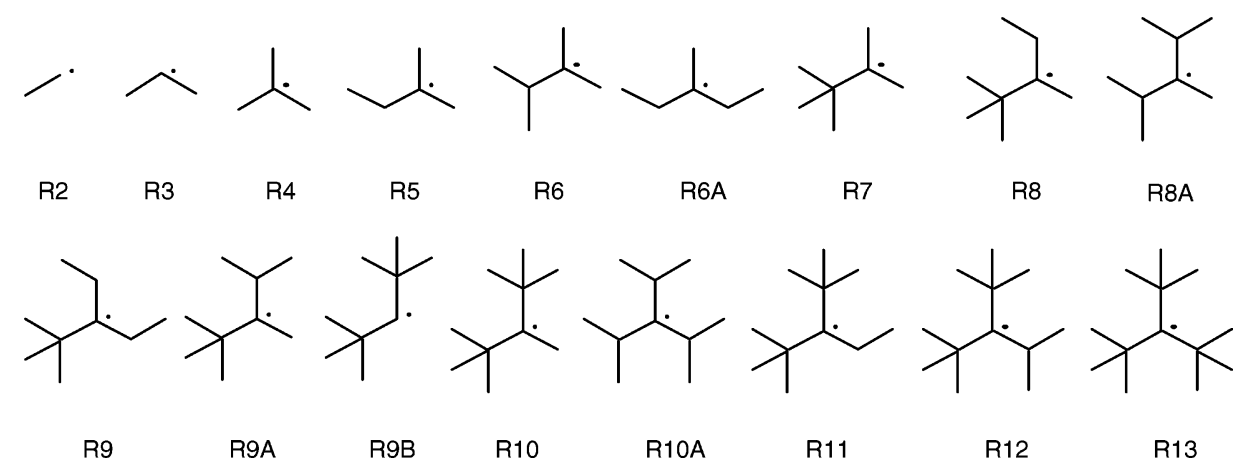

Figure 8. Radicals.

Table 6. DFT Energies for Radicals (Hartrees) ${ }^{a}$

$\begin{array}{llllll}\text { R2 } & -79.16520774854 & \text { R6 } & -236.44141394816 & \text { R9A } & -354.38378662222 \\ \text { R3 } & -118.48825812798 & \text { R7 } & -275.75462840399 & \text { R9B } & -354.37798726942 \\ \text { R4 } & -157.81103171053 & \text { R8 } & -315.06979991161 & \text { R10 } & -393.68689481392 \\ \text { R5 } & -197.12621736302 & \text { R8A } & -315.07168589029 & \text { R10A } & -393.70199962957 \\ \text { R6A } & -236.44117164352 & \text { R9 } & -354.38445080993 & \text { R11 } & -433.00067180947 \\ & -236.44097156706 & & -354.38286518553 & \text { R12 } & -472.30673041978 \\ & & & & \text { R13 } & -511.59468374195\end{array}$

${ }^{a}$ R6A and R9 have two low-energy conformations.
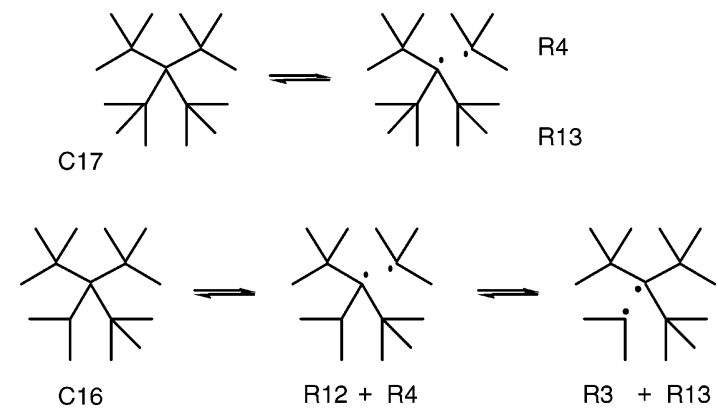

Figure 9. Fragmentation reactions.

in the minimized structures give very small energies differences when compared to the isolated radicals, as expected.

Adding a correction for the zero point energy of the species, $\mathrm{C} 18$ becomes the smallest structure that is more energetic as a single molecule than a pair of radicals. However, both $\mathrm{C} 17$ and $\mathrm{C} 16$ prefer to be a single molecule by only a very small amount. C15 is substantially more stable.

In 1900, Gomberg attempted to make hexaphenylethane (11) and instead discovered a structure he assigned to be a triphenylmethyl radical (12). ${ }^{28}$ Later studies showed that the molecule was the dimer 13 and not a stable radical. ${ }^{29}$ The triphenylmethyl radical cannot easily fragment and can undergo an addition reaction. The highly branched alkyl radicals that would be formed by homolytic bond cleavage from crowded alkanes would rapidly break up to even smaller structures.

The data in Table 7 show that $\mathrm{C} 18$ and smaller molecules have an enthalpic preference to be single molecules. Larger
Table 7. DFT Energies for More Alkanes

\begin{tabular}{|c|c|c|c|c|}
\hline structure & energy (hartrees) & $\begin{array}{c}\text { longest } \\
\mathrm{C}-\mathrm{C} \\
\text { bond } \\
(\AA)\end{array}$ & $\begin{array}{c}\text { energy } \\
\text { relative } \\
\text { to radicals } \\
\left(\mathrm{kJ} \mathrm{mol}^{-1}\right)\end{array}$ & $\begin{array}{l}\text { energy relative } \\
\text { to radicals with } \\
\text { zero point } \\
\text { energies } \\
\left(\mathrm{kJ} \mathrm{mol}^{-1}\right)\end{array}$ \\
\hline $\mathrm{C} 13$ & -512.24983609491 & 1.621 & -159.71 & -125.65 \\
\hline $\mathrm{C} 14$ & -551.54584105441 & 1.650 & -132.57 & -98.54 \\
\hline $\mathrm{C} 15$ & -590.84376104978 & 1.664 & -84.18 & -49.93 \\
\hline $\mathrm{C} 16$ & -630.13420949933 & 1.676 & -43.19 & -7.42 \\
\hline $\mathrm{C} 17$ & -669.41956935300 & 1.688 & -36.38 & -4.98 \\
\hline $\mathrm{C} 18$ & -708.72584056646 & 1.701 & -12.97 & 21.97 \\
\hline C19 & -748.018040741686 & 1.722 & 47.42 & 83.90 \\
\hline C19A & -748.02918612978 & 1.722 & 17.51 & \\
\hline $\mathrm{C} 20^{a}$ & -787.29807339840 & 1.824 & 134.55 & 170.55 \\
\hline C20A & -787.35959331052 & 1.871 & 116.61 & \\
\hline $\mathrm{C} 21$ & -826.59868421412 & 1.935 & 172.79 & \\
\hline $\mathrm{C} 21 \mathrm{~A}$ & -826.60495104989 & 1.837 & 161.29 & \\
\hline C22 & -865.91521887467 & 4.473 & 166.15 & \\
\hline $\mathrm{C} 22 \mathrm{~A}$ & -865.91920436862 & 4.425 & 157.38 & \\
\hline C23 & -905.28238274086 & 5.404 & -2.11 & \\
\hline C26 & -1023.18735827342 & 5.680 & 5.28 & \\
\hline
\end{tabular}

${ }^{a}$ A second minimum energy structure was found for C20, corresponding to two radicals adjacent to each other. This structure had an energy of $-1.02 \mathrm{~kJ} \mathrm{~mol}^{-1}(-787.34969875170$ Hartree) and a C-C 'bond' length of $5.1 \AA$.

molecules have an enthalpic preference to homolytically dissociate into radicals. When zero point energy corrections are considered, $\mathrm{C} 17$ is the largest molecule which prefers to be a single molecule. Entropic effects will further favor dissociation, and so these results suggest that $\mathrm{C} 17$ is the largest alkane from this series that could possibly be isolated, although the enthalpic balance for this molecule is only just

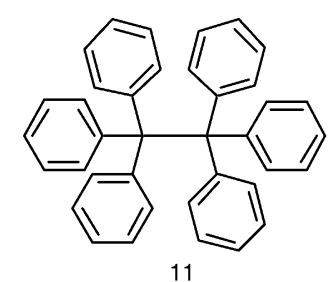

11

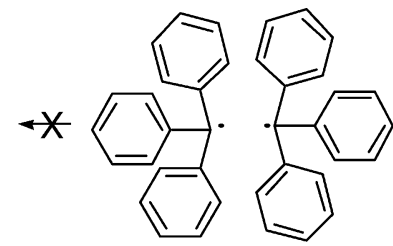

12

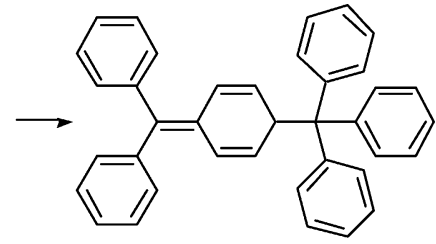

13

Figure 10. Triphenylmethyl radical. 
in favor of the single molecule. At the same level of theory, the dissociation of $t$ - $\mathrm{BuOO} t$ - $\mathrm{Bu}$ (a commonly used radical initiator) is endothermic by $147 \mathrm{~kJ} \mathrm{~mol}^{-1}$. The activation energy for the dissociation has been experimentally determined $^{30}$ as $152 \pm 0.6 \mathrm{~kJ} \mathrm{~mol}^{-1}$. This suggests the calculated values for the dissociation energies are reasonable. Comparison of the figures in Table 7 with those in Table 4 (estimates of the barrier for dissociation) for $\mathrm{C} 15, \mathrm{C} 16$, and $\mathrm{C} 17$ shows that the thermodynamic figures in Table 7 are of comparable magnitude to the kinetic barriers but slightly smaller in all cases, as should be expected. Thus Table 7 shows that $\mathrm{C} 16$ and $\mathrm{C} 17$ have rather similar properties thermodynamically, and Table 4 shows that both may be expected to dissociate rapidly at room temperature. While it is possible that one of these molecules is accessible and the other is not, the similarity of the results suggests that they will have similar properties. We conclude, therefore, that neither will be made.

\section{CONCLUSION}

All these analyses agree that $\mathrm{C} 15$ should be stable at room temperature, and so the synthesis of this molecule should be possible, although it may well undergo thermolysis on moderate heating. Our first, and least accurate, analysis (AM1) suggests that $\mathrm{C} 21$ may be stable, but this is not supported by the other analyses. The strain energy analysis and the DFT calculations suggest that the limit of stability lies either at $\mathrm{C} 15$ or $\mathrm{C} 16$, and so the smallest alkane that can never be made will be either $\mathrm{C} 16$ or $\mathrm{C} 17$, except perhaps at very low temperatures for a short time. We are confident that $\mathrm{C} 17$ could never be made and suggest that $\mathrm{C} 16$ is the smallest saturated alkane that cannot be made.

\section{ACKNOWLEDGMENT}

KMNdeS thanks the Asian Development Bank for financial assistance under the Science and Technology Personnel Development Project and Dr. Nick Bampos for hosting his study in Cambridge.

\section{REFERENCES AND NOTES}

(1) Goodman, J. M. What is the Longest Unbranched Alkane with a Linear Global Minimum Conformation? J. Chem. Inf. Comput. Sci. 1997, 37, 876-878.

(2) Nair, N.; Goodman, J. M. Genetic Algorithms in Conformational Analysis. J. Chem. Inf. Comput. Sci. 1998, 38, 317-320.

(3) Michl, J., Gladysz, J. A., Eds.; Strained Organic Compounds. Chem. Rev. 1989, 89, \#5, 974-1270.

(4) Alder, R. W.; Maunder, C. M.; Orpen, A. G. The Conformational Effects of Quaternary Centres. Tetrahedron Lett. 1990, 46, 67176720.

(5) Wiebenga, E. H.; Bouwhuis, E. Strain in Tertiary Butyl Derivatives. Tetrahedron 1969, 25, 453-457.

(6) Irloff, L. D.; Mislow, K. Molecules with T Symmetry. Conformational Analysis of Systems of Type $\mathrm{M}\left[\mathrm{C}\left(\mathrm{CH}_{3}\right)_{3}\right]_{4}$ and $\mathrm{M}\left[\mathrm{Si}\left(\mathrm{CH}_{3}\right)_{3}\right]_{4}$ by the Empirical Force Field Method. J. Am. Chem. Soc. 1978, 100, 21212126.

(7) Cheng, M. F.; Li, W. K. Structural and energetics studies of tri and tetra-tert-butylmethane. J. Phys. Chem. A 2003, 107, 5492-5498.
(8) Kuck, D.; Schuster, A.; Krause, R. A. Synthesis and Conformational Behavior of Fenestrindans (Tetrabenzo[5,5,5,5]fenestranes) with Four Bridgehead Substituents. J. Org. Chem. 1991, 56, 3472-3475.

(9) Rüchardt C.; Beckhaus, H.-D.; Hellmann, G.; Weiner, S.; Winiker, R. Observation of a Linear Relationship between Thermal Stability and Strain Energy of Alkanes. Angew. Chem., Int. Ed. Engl. 1977, 16, 875-876.

(10) Mendenhall, G. D.; Ingold, K. U. Di- and Tri-tert-butylmethyl, Two Aliphatic Radicals of Unusual Stability. J. Am. Chem. Soc. 1973, 95, 3422-3423.

(11) Favorsky. A. E.; Nazarov, I. N. Action of Metallic Sodium on Aliphatic Ketones. The Question of the Existence of Metal Ketyls in the Aliphatic Series. Bull. Soc. Chim. Fr. 1934, 1, 46-63.

(12) Stevens, P. G.; Mowat, J. H. The Action of Sodium on Hexamethylacetone. J. Am. Chem. Soc. 1942, 64, 554-556.

(13) Bucher, G. Revisiting the Reduction of Di-tert-butyl Ketone with Alkali Metals. Eur. J. Org. Chem. 2003, 2229-2232.

(14) Klein, D. J. Rigorous Results for Branched Polymer Models with Excluded Volume. J. Chem. Phys. 1981, 75, 5186-5189.

(15) Allinger, N. L. Conformational Analysis. 130. MM2. A Hydrocarbon Force Field Utilizing $\mathrm{V}_{1}$ and $\mathrm{V}_{2}$ Torsional Terms J. Am. Chem. Soc. 1977, 99, 8127-8134.

(16) Mohamadi, F.; Richards, N. G. J.; Guida, W. C.; Liskamp, R.; Lipton, M.; Caufield, C.; Chang, G.; Hendrickson, T.; Still, W. C. MacroModel- an Integrated Software System for Modeling Organic and Bioorganic Molecules using Molecular Mechanics. J. Comput. Chem. 1990, 11, 440-467.

(17) Chang, G.; Guida, W. C.; Still, W. C. An Internal Coordinate Monte Carlo Method for Searching Conformational Space. J. Am. Chem. Soc. 1989, 111, 4379-4386.

(18) Dewar, M. J. S.; Zoebisch, E. G.; Healy, E. F.; Stewart, J. J. P. The Development and Use of Quantum-Mechanics Molecular-Models. 76. AM1- A New General-Purpose Quantum-Mechanical MolecularModel. J. Am. Chem. Soc. 1985, 107, 3902-3909.

(19) MOPAC93. J. J. P. Stewart MOPAC- a Semiempirical Molecular Orbital Program. J. Comput.-Aided Mol. Des. 1990, 4, 1-45.

(20) MMFF force field: Halgren, T. A. Merck molecular force field. 1. Basis, form, scope, parametrization, and performance of MMFF94. $J$. Comput. Chem. 1996, 17, 490-519.

(21) Davies, R. E.; Freyd, P. J. $\mathrm{C}_{167} \mathrm{H}_{336}$ is the Smallest Alkane with More Realizable Isomers than the Observed Universe has "Particles". $J$. Chem. Educ. 1989, 66, 278-281.

(22) Velevkin, S. P.; Nölke, M.; Beckhaus, H.-D.; Rüchardt C. Enthalpies of formation of Hexaethylethane, Octamethylhexane, and Tri-tertbutylmethane. Extremely Strained Hydrocarbons. J. Org. Chem. 1997, 62, 4683-4686

(23) Lomas, J. S.; Dubois, J.-E. Thermolysis of Highly congested tertButyldialkylcarbinols with Bridgehead Substituents: Molecular Mechanics Treatment of Radical-Forming Processes. J. Org. Chem. 1982 47, 4505-4511.

(24) Allen, F. H. The Cambridge Structural Database: a Quarter of a Million Crystal Structures and Rising. Acta Crystallogr. 2002, B58, 380-388.

(25) Toda, F.; Tanaka, K.; Watanabe, M.; Tamura, K.; Miyahara, I.; Nakai, T.; Hirotsu, K. Extremely Long C-C Bond in (-)-trans-1,2-Di-tertbutyl-1,2-diphenyl- and 1,1-Di-tert-butyl-2,2-diphenyl-3,8-dichlorocyclobuta $[b]$ naphthalenes. J. Org. Chem. 1999, 64, 3102-3105.

(26) Meer, M. A. F.; Beckhaus, H.-D.; Peters, K.; von Schnering, H.-G.; Fritz, H.; Rüchardt, C. Thermolabile Hydrocarbons. XXVIII. Separation, Structure, Analysis, and Thermolysis of a Pair of Stable Rotamers - P- $\left(R^{*}, R^{*}\right)$ and $\mathrm{M}-\left(R^{*}, R^{*}\right)-\mathrm{D}, \mathrm{L}-3,4-d i-1$-adamantyl-2,2,5,5-tetramethylhexane. Chem. Ber. 1986, 119, 1492-1510.

(27) Macromodel v5; Maestro; Jaguar version 4.2: Schrodinger, Inc., Portland, Oregon, 2000.

(28) Gomberg, M. An instance of trivalent carbon: triphenylmethyl. J. Am. Chem. Soc. 1900, 22, 757-771.

(29) Eberson, L. Gomberg and the Nobel Prize. Adv. Phys. Org. Chem. 2001, 36, 59-84

(30) Griffiths, J. F.; Singh, H. J. Effects of Self-heating During the Thermal Decomposition of di-tert-Butyl Peroxide. J. Chem. Soc., Faraday Trans. 1 1982, 78, 747-760.

CI0497657 